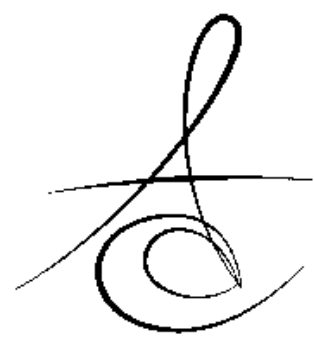

\title{
KOMBİNE ORTODONTİK CERRAHİ TEDAVİDE STABİLİTEYİ ETKİLEYEN FAKTÖRLER
}

\section{THE FACTORS EFFECTING STABILITY OF COMBINED ORTHODONTIC- SURGICAL TREATMENT}

\author{
Dt. Emel Yeşíl ŞAHİN*ºr. Tülin TANER*
}

Makale Kodu/Article code: 2137

Makale Gönderilme tarihi: 13.02.2015

Kabul Tarihi; 27.04.2015

\section{ÖZET}

Kombine ortodontik cerrahi tedavi sonrası kısa ve uzun dönem stabilite, ortognatik cerrahi işleminin tanıtıldığı ve uygulamaya gectiği günden bugüne büyük bir problemdir; çünkü estetik ve fonksiyonel sonuçlar, cerrahi sonrası stabilite ile direkt olarak ilişkilidir. Kombine ortodontik cerrahi tedavi sonrası stabiliteyi etkileyen birçok faktör bulunmaktadır. Literatürde bu faktörler dikkate alınarak planlama yapıldığında başarılı sonuçlar elde edildiğini gösteren çalışmalar bulunmaktadır. Stabilite ortodontik tedavinin olduğu kadar ortognatik cerrahinin de hedefinde olmalı ve stabilite eksikliği bir komplikasyon olarak kabul edilmelidir. Bu derlemenin amacı, kombine ortodontik cerrahi tedavide stabilite üzerine yapılmış çalışmaları değerlendirmek ve stabiliteyi etkileyen faktörleri belirlemektir.

Anahtar Kelimeler: Kombine ortodontik cerrahi tedavi, ortognatik cerrahi, stabilite

\section{KOMBİNE ORTODONTİK CERRAHİ TEDAVİDE STABİLİTEYİ ETKİLEYEN FAKTÖRLER}

Başarılı bir kombine ortodontik cerrahi tedavinin hedefleri arasında normal çene ilişkilerinin kurulması, uygun yüz estetiğinin ve uzun dönem stabilitenin sağlanması yer almaktadır. Ortognatik cerrahide stabilite birçok faktörden etkilenebilmektedir. Bunlar sırasıyla;

\section{1) Ayırıcı tanı ve uygun hasta:}

Ortognatik tedaviden en çok fayda görecek hastaların belirlenebilmesi için doğru ayırıcı teşhis önem taşımaktadır. Örneğin ortodontist, büyümeye devam eden bir Sını 3 hastanın mandibular aşırılık durumuna sahip olup olmadığını belirlemelidir. Sınır olgu

\section{ABSTRACT}

The short and long-term stability after combined orthodontic surgical treatment is a major problem since orthognathic surgery had been introduced and performed, because aesthetic and functional results are directly associated with postoperative stability. There are many factors that affect stability after combined orthodontic surgical treatment. Studies that are considering these factors, present successful result in the literature. Stability should be the target of orthognathic surgery as in orthodontic treatment and the lack of stability should be considered as a complication. Therefore, the aim of this review is to determine the factors that affect the stability of orthodontic surgical treatment and evaluate the studies on stability.

Key Words: Combined orthodontic surgical treatment, orthognathic surgery, stability

olgularda iskeletsel düzeltim ve fonksiyonel kaymalar açısından erken ortodontik tedavi yapılabilir. Diğer olgularda ise çoğunlukla cerrahi gerekli olduğundan, cerrahi öncesi hazırlık için daha geç yaşta tedaviye başlanabilir. ${ }^{1}$

\section{2) Büyüme ve cerrahi zamanlaması:}

Tedavi sonrası büyüme, tedavi sonuçlarının stabilitesini bozan bir faktördür. Proffit ve White ${ }^{2}$ yaptıkları çalışmada stabilitenin sağlanmasında en önemli faktörün büyüme ve gelişme olduğunu, hastalar hala büyüyorsa ameliyat edilmemeleri gerektiğini bildirmişlerdir. Hastanın tedavisi tamamlandıktan sonra büyüme ortodontik düzeltimi olumsuz etkiliyorsa, hastaya bu aşamada cerrahi önerildiğinde kolaylıkla

* Hacettepe Üniversitesi, Diş Hekimliği Fakültesi, Ortodonti Anabilim Dalı 
kabul etmeyebilir. Bu nedenle büyümenin önceden tahmin edilmesi ve hastanın bilgilendirilmesi önem taşımaktadır.

Graber ve ark.larına ${ }^{1}$ göre büyüme ile ilişkili komplikasyonları önlemek için aşağıdaki faktörler dikkate alınmalıdır;

-Orta şiddetli Sınıf 3 mandibular aşırılığa sahip hastalarda cerrahi, sefalometri ile mandibula büyümesinin tamamlandığı doğrulanana kadar ertelenmelidir. Erkeklerde bu 22-24 yaş kadar geç olabilir.

-Asimetri ve tek taraflı hipertrofiye sahip hastalarda cerrahi, kemik taramaları hipertrofik kondilde büyüme aktivitesinin durduğunu gösterene kadar ertelenmelidir. Eğer büyüme durmazsa, cerrahiden sonra asimetrinin tekrar oluşmaması için mümkün olduğunca erken bir dönemde kondilektomi işlemi uygulanmalıdır. ${ }^{3}$

-Mandibular yetersizliğe sahip hastalarda cerrahinin büyüme tamamlanmadan önce başarıyla yapılabildiği rapor edilmiştir. Erkeklerde mandibulanın Sınıf 1 düzeltimi geçecek şekilde büyüme riski vardır, ancak mandibular ilerletmenin relaps eğilimi mandibulanın geç diferensiyel büyüme atılımı ile dengelenebilir.

-Aşırı vertikal büyümeye sahip bazı hastalarda maksillada Le Fort I osteotomisi büyüme tamamlanmadan önce düşünülebilir. Fakat mandibular yetersizliğe sahip hastalarda erken çift çene cerrahi, mandibula aşağıya ve geriye büyümeye devam ediyorsa stabil olmayacak ve kapanış tekrar açılacaktır. ${ }^{4}$ Snow ve diğerleri ${ }^{5}$ cerrahi sonrasında mandibular büyümenin vertikal düzlemde olduğunu ve bu durumun da relapsa neden olduğunu rapor etmişlerdir.

-Maksiller transvers yetersizliğe sahip hastalar için ortopedik ekspansiyon kızlarda 14, erkeklerde 16 yaşına kadar etkili olabilir. Daha geç yaşlarda her iki cinsiyette özellikle cerrahi desteği ile başarılı ortopedik ekspansiyon rapor edilmiştir. Hastanın yaşı arttıkça cerrahisiz ortopedik ekspansiyon başarısının tahmin edilebilirliği azalmaktadır.

\section{3) Temporomandibular eklem (TME) ve kondil pozisyonunun stabilitesi:}

Ortodonti literatürü tekrarlanabilir kondil fossa ilişkisine dayanan tedavi planlamasının önemini vurgulamaktadır. Stabil kondil pozisyonu, cerrahi öncesi değerlendirmeye, proksimal segmentin cerrahi kontrolüne, hastanın cerrahi sonrası yeni nöromuskuler ve fonksiyonel çevreye adaptasyonuna bağlıdır.
Oklüzyonda fonksiyonel kayma problemlerinin belirlenmesi önemlidir. Bu yapılmazsa fonksiyonel kayma, vakanın olduğundan daha iyi görünmesine ya da olduğundan daha kötü görünmesine neden olabilir ve başarısız tedavi planlaması ile sonuçlanır. Tedaviden önce mandibuler kaymaların teşhisi, repositioning splintleri (konumlandırma splintleri) kullanılarak, kondil yerleşimi ölçülerek ya da mandibula dikkatle yönlendirilerek yapılabilir.

Eğer bu uyumsuzluklar tedavi öncesinde belirlenmemişse ve tedavi sırasında ortaya çıkmışsa klinisyen hastayı bilgilendirmeli ve tedavi planlamasında değişiklikler önermelidir. Mandibulanın sentrik ilişkideki pozisyonu tedavi planı tam olarak yapılmadan önce belirlenmelidir. ${ }^{6}$

Gunson ve ark. ${ }^{7}$ kadınlarda idiyopatik kondil rezorpsiyonunun geç kondiler değişikliklerin nedeni olabileceğini bildirmişlerdir. Bu bulgular sonucunda yazarlar, bayanların küçük bir kısmında artan kondil yüklemesine bağlı kondil rezorpsiyonu oluşabileceğini, fakat çoğu kadında bu durumun iyi tolere edilebildiğini göstermişlerdir. Moore ve diğerleri ${ }^{8}$, kondil rezorpsiyonunu göz önünde bulundurarak cerrahi relaps açısından literatürü incelemişler ve sonuçta, kondil rezorpsiyonu açısından yüksek risk grubunda olan bireyleri 20-30 yaş arasında yüksek mandibular düzlem açısına ve cerrahiden önce TME bulgularına sahip olan kadınlar olarak bulmuşlardır.

Kim ve ark. ${ }^{9}$ tarafından yapılan ve iskeletsel Sınıf 3 maloklüzyona sahip 33 hastanın üç boyutlu radyografik görüntüleri kullanılarak cerrahiden 1 yıl sonra kondil pozisyonundaki değişikliklerin stabiliteye etkisini değerlendiren çalışmada, kondilin cerrahiden sonra 3. ayda anteriora yer değiştirdiği, 6. ayda distal yönde hareket ettiği ve daha sonra stabil kaldığı bulunmuştur. $\mathrm{Bu}$ hareketler cerrahinin stabilitesini olumsuz yönde etkilemektedir.

\section{4) Dental stabilite:}

Dental stabilite TME stabilitesi kadar önem taşır. Örneğin periodontal hastalık nedeniyle kemik kaybına ya da yapısal olarak kısa köklere bağlı uygun olmayan kron/ kök oranı oluşabilir. ${ }^{10}$ Böyle bir durumda ortodontist, dişlerdeki mobilite problemlerini belirlemeli ve cerraha interdental fiksasyon yerine iskeletsel fiksasyonu önermelidir. Stabil olmayan dental durumun başka bir nedeni simante edilen geçici kronlar olabilir. Geçici kronlar üzerinden braketler kolayca kopabilir, kronlar dişlerden kolayca uzaklaşabilir. Bu

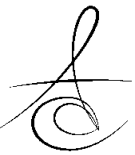


nedenlerden dolayı geçici kronlara sahip hastalarda interdental fiksasyon önerilmez. ${ }^{1}$

\section{5) Nöromuskuler adaptasyon:}

İskeletsel yapıları değiştiren cerrahi işlemler, stomatognatik sistemin nöromuskuler yapısında da değişikliklere neden olur. Ortognatik cerrahiyi uygulayan ekip için iskeletsel yapılar, dental yapılar ve kasların dengesini sağlamak biyolojik bir zorluktur. Günümüzde uygulanan cerrahi işlemler bilimsel hipotezlere dayansa da, relaps problemleri tedavinin bir kısmının deneysel komponentlere sahip olduğunu göstermektedir. ${ }^{1}$

\section{6) Cerrahın becerisi}

Cerrah, tedavi planlamasındaki cerrahi hedeflerini gerçekleştirebilecek bilgi ve beceriye sahip olmalıdır. Sefalometrik cerrahi ve artikülatöre alınmış modeller üzerinde planlanan hareket miktarları, cerrahiye bire bir yansıtılmaya çalışılmalıdır. ${ }^{11,12}$

\section{7) Osteotomi tasarımı:}

Cerrahi işlem sırasında osteotomi hatları, kan akımının bozulmaması için iyi planlanmalı, işlem sonrasında iyileşme problemleri nedeniyle stabil olmayan bir durumla karşılaşılmamalıdır. ${ }^{1}$

\section{8) Hareket miktarı:}

Maksiller vertikal yetersizlik ve mandibular horizontal yetersizliklerde cerrahi düzeltimin miktarı artarsa stabilitenin azalacağı bildirilmiştir. ${ }^{1}$

Epker ve diğerlerinin ${ }^{13}$ çalışmasında da, daha büyük hareket miktarlarının daha fazla relapsa neden olduğu rapor edilmiştir.

9) Yumuşak dokuların ve kasların gerilimsiz olması:

Wickwire ve diğerler ${ }^{14}$ Sınıf 2 mandibular cerrahi hastalarında hyoidin öne ve yukarıya hareketinin, cerrahinin stabilitesini etkileyen en önemli faktör olduğunu, bir diğer etkenin ise kas gerilimleri olduğunu bildirmişlerdir. Örneğin; mandibular ilerletme yumuşak doku ve kaslarda gerilime neden olacağından, gerilimi azaltmak için mandibula ilerletilirken ön tarafı aşağı arka tarafı yukarı hareket ettirilebilir. ${ }^{1}$

Poulton ve Ware ${ }^{15}$ relapsın en güçlü nedeninin suprahyoid kasların uzaması olduğunu rapor etmişlerdir. McNeill ve diğerleri ${ }^{16}$ ise, fiksasyon sırasında yumuşak doku ve kasların gerilimi nedeniyle mandibulanın geriye migrasyonunun relapsa neden olduğunu bildirmişlerdir.

İntermaksiller fiksasyon sırasında immediyat postoperatif relaps tespit edilmesi sonucunda relapsın önlenmesi için suprahyoid miyotomi ile kombine mandibular cerrahi önerilmiştir. ${ }^{17,18}$

\section{0) Mandibular rotasyonun tipi:}

Mandibulanın aşağı geri rotasyonu yukarı öne rotasyonundan daha stabil bulunmuştur. ${ }^{1}$

Ancak, Bailey ve diğerlerinin ${ }^{19}$ yaptıkları çalışmada okluzal düzlemin değişmesi ile sonuçlanan saat yönünün tersine rotasyonun da stabil olabileceği bildirilmiştir.

11) Kompanzasyon mekanizmalarının azaltılması için cerrahi öncesi ortodontik hazırlık:

Cerrahi öncesi ortodontik hazırlıkta ark seviyelenmesi 2.molarları da içermelidir. Mandibular aşırılık vakalarında üst 2.molarlar, mandibular yetersizlik olgularında alt 2.molarlar aşııı uzayabilir. Bu dişler vertikal olarak seviyelenmemişse cerrahi sırasında doğru okluzyon sağlanamayabilir, bu da kondiler distraksiyona ve stabil olmayan duruma neden olur. ${ }^{1}$

İskeletsel Sınıf 3 maloklüzyona sahip, cerrahi öncesi hazırlık yapılarak ve yapılmadan (surgery-first tekniği ile) mandibular geriletme yapılan 61 hastada cerrahi sonrası horizontal relaps miktarı, surgery-first grubunda daha yüksek bulunmuştur. Bu nedenle surgery-first yapılması planlandığında stabilitenin düşünülmesi gerektiği sonucuna varılmıştır. ${ }^{20}$

Ancak başka bir çalışmada, cerrahi öncesi hazırlık yapılan ve surgery-first tekniği ile tedavi edilen Sınıf 3 cerrahi hastalarında cerrahi sonrası stabilite, iskeletsel ve dental değişiklikler bakımından anlamlı farklılık bulunamamışır. ${ }^{21}$

\section{2) İntermaksiller fiksasyon süresi ve} yöntemi:

Hartlev ve diğerleri ${ }^{22}$ tek çene mandibular ilerletme yapılan, cerrahiden sonra intermaksiller fiksasyon uygulanan ve uygulanmayan 26 hastada yaptıkları çalışmada cerrahiden 18 ay sonra gruplar arasında iskeletsel stabilite açısından anlamlı farklıık bulamamışlardır. Krekmanov ve Lilja ${ }^{23}$ intermaksiller fiksasyon uygulamadıkları 113 çift çene cerrahi hastasında, cerrahi sonrası az miktarda komplikasyon ve uygun stabilite bulunduğunu rapor etmişlerdir. Bu çalışmada cerrahide rijit fiksasyon tercih edildiğinde intermaksiller fiksasyona gerek kalmadığı sonucuna varılmıştır. Yine Krekmanov ${ }^{24}$ intermaksiller fiksasyon uygulamadan yaptığı cerrahiler sonucunda, cerrahiden en az 1 yıl sonra maksilla pozisyonunun değişmediğini, mandibulada ise geriletme vakalarında hafif yukarı

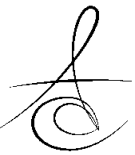


öne rotasyon görüldüğünü rapor etmiştir. Bu nedenle tüm hastalarda değil, hastada nazal solunum varsa ve dişler sıkı kontakta değilse intermaksiller fiksasyon yapılabileceğini vurgulamıştır.

\section{3) Cerrahi planlaması:}

Proffit ve diğerleri ${ }^{25}$, Sınıf 3 maloklüzyona sahip hastalarda sadece mandibular geriletme cerrahisi ile çift çene cerrahinin stabilite açısından sonuçlarını karşılaştırmak amacıyla bir çalışma yapmışlardır. Çalışmada hastaların tümünde ortalama $4,7 \mathrm{~mm}$ geriletme, çift çene grubunda buna ek olarak ortalama 4,9 mm maksiller ilerletme yapılmış ve çene ucu ve gonion pozisyonu, ramus açısı ve buna bağlı relaps görülme oranı değerlendirilmiştir. Her iki grupta da değerler benzer bulunmuş ancak sadece mandibular geriletme yapılan grupta bu durum ramus açısındaki değişime bağlanırken, çift çene grubunda maksillayla beraber mandibulanın rotasyon yapmasına bağlanmıştır. Ramus pozisyonunun kontrolü açısından bu hastalarda çift çene cerrahi yapılması tavsiye edilmiştir.

Al-Delayme ve diğerlerinin ${ }^{26}$ yaptıkları çalışmada ise, iskeletsel Sınıf 3 malokluzyona sahip 24 hastaya tek ve çift çene cerrahi uygulanmış ve cerrahiden sonra en az 12 ay takip edilen hastalarda maksiller stabiite benzer bulunurken, tek çene cerrahi hatsalarında mandibular horizontal stabilitede yetersizlik bulunmuştur.

\section{4) Fiksasyon türü:}

Cerrahide fiksasyon dental, iskeletsel, rijit, semirijit ya da bunların birlikte kullanımı şeklinde olabilir. Bu fiksasyon yöntemlerinden iskeletsel ve rijit fiksasyonun relapsı ciddi oranda azalttığı bilinmektedir. ${ }^{1}$

Fiksasyon yapıldığında eğer kondil glenoid fossa içerisinde değilse 'immediyat postoperatif relaps 'görülür. İlk 6-8 hafta içeisinde görülen bu relaps 'erken dönem relaps' olarak adlandırılır ve nedeni fiksasyon yöntemindeki başarısızlık ya da osteotomi alanındaki harekettir. Bunu önlemek için daha stabil olduğu düşünülen rijit fiksasyon tercih edilir. ${ }^{27}$

Ancak Arnett ve ark. ${ }^{28}$, rijit fiksasyondan sonra kondilin posterior pozisyonunun progresif kondiler rezorpsiyona ve buna bağlı geç dönem relapsa neden olduğunu savunmuşlardır.

Progresif kondiler rezorpsiyon kondilde şekil değişikliği ve kondiler yükseklikte azalma ile karakterizedir ve 6-17 ay içerisinde meydana gelir. Literatürde uzun dönemde relapsın nedeni olarak görülen bu duruma, tek çene ya da çift çene farketmeksizin $\% 2,3$ ila $\% 7,7$ oranında rastlanır. ${ }^{8,} 29$ Böylece uzun dönem stabilite problemleri, sinir hasarı olasılığında artış, TME ve dişlerde yüklenmeler ve olası cerrahi hatalar nedeniyle fiksasyon yöntemini değiştirmeye yönelik arayışlar ortaya çıkmıştır.

Semirijit fiksasyonda amaç, osteotomi yapılan alanlarda fonksiyonel stabilite elde etmek ve TME fonksiyonlarını olumsuz etkilememektir. Bu yöntem osteotomi alanlarının vertikal hareketini önlerken, rotasyonel hareketlere izin verir. Semirijit fiksasyonda maksillada nazomaksiller butressa 2 adet L-şekilli mini plak, mandibulada ise sağ ve solda ikişer adet $2 \mathrm{~mm}$ çapında bikortikal vida kullanılır. Böylece hem operasyon zamanı kısalır, hem de maliyet azalır. ${ }^{30}$ Bikortikal vidalar az miktarda kondil rotasyonuna izin verdiği için tercih edilmektedir.

Blomqvist ve Isaksson, ${ }^{31}$ bikortikal vida ile plak-monokortikal vida tekniğinin stabilitesini karşılaştırmak amacıyla yaptıkları çalışmada iki yöntem arasında fark bulamamış, ancak uzun dönemde her iki grupta da stabilitenin azaldığını tespit etmişlerdir.

Mavili ve ark. ${ }^{30}$ semirijit fiksasyonun kısa ve uzun dönem stabiliteye etkisini araştırmak amacıyla yaptıkları çalışmada, ortalama yaşları 22 olan 23'ü çift çene, 12'si tek çene cerrahi geçiren ve semirijit fiksasyon kullanılan hastaların cerrahiden 1 ay önce, en az 15 günlük intermaksiller fiksasyon sonrası ve tedavi tamamlandıktan sonra alınan sefalometrik filmlerini değerlendirmişler ve hem kısa hem de uzun dönem stabilitede anlamlı farklılık bulamamışlardır.

Ellis ve ark. $^{32}$ ise farklı fiksasyon yöntemleri kullanarak stabiliteyi değerlendirmişler ve yöntemden bağımsız olarak tüm gruplarda relaps olduğunu, sonuç olarak en stabil durumun rijit fiksasyon en fazla relaps görülen durumun ise tel fiksasyonu ile olduğunu bildirmişlerdir.

\section{5) Cerrahi işlemin tipi:}

Proffit ve $a k^{33}, 3000$ hasta üzerinde yaptıkları çalışmanın sonucu olarak stabiliteyi 4 aşamada değerlendirmişler ve tedavi sonrası değişiklikleri;

-\%10'dan az ise 'yüksek oranda stabil',

-\%20'den az ise 'stabil',

-'sadece rijit internal fiksasyonla stabil' ve

- 'problemli'olarak kategorize etmişlerdir.

Stabilite hiyerarşisine göre, en stabil hareket grubunu maksillanın yukarı hareketi ve mandibulanın ileriye hareketi oluşturmaktadır. Daha sonra sırasıyla, maksillanın öne hareketi, maksillanın yukarı-mandibu-

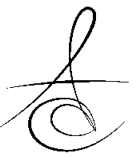


lanın öne hareketi, maksillanın öne-mandibulanın geriye hareketi, asimetri düzeltimi, mandibulanın geriye hareketi, maksiller sarkıtma ve maksiller genişletme işlemleri stabil olarak değerlendirilmektedir. ${ }^{33}$

\section{Maksiller gömme:}

Çoğu yazar maksillanın yukarı hareketinin en stabil hareket olduğu konusunda hemfikirdir. Proffit ve ark. $^{34}$ tel fiksasyon yöntemiyle maksiller gömme cerrahisi uygulanan hastaların \%80'inde maksillanın anteriorunun vertikal olarak stabil kaldığını bildirmişlerdir. Yine Bailey ve diğerlerinin ${ }^{35}$ çalışmasında, minimum $2 \mathrm{~mm}$ gömme yapılan ve rijit fiksasyon kullanılmayan 49 hastanın en az 5 yıl takibinde orta seviyede iskeletsel ve dental değişiklik görülmüştür.

\section{Maksiller ilerletme:}

Rijit fiksasyonla kemik grefti uygulanmadan ortalama 3,7 mm maksiller ilerletme yapılan 11 hastada anlamlı relaps görülmemiştir. ${ }^{36}$ Louis ve diğerleri ${ }^{37}$ uyku apnesine sahip hastaları maksillomandibular ilerletme cerrahisi öncesinde ortalama 4,7 mm, 8,2 $\mathrm{mm}$ ve $12,3 \mathrm{~mm}$ maksiller ilerletme miktarına göre 3 gruba ayırmış, cerrahi sonucunda semirijit fiksasyonla çok hafif relapsla birlikte gruplar arasında anlamlı bir fark bulamamışlardır.

de Haan ve ark. ${ }^{38}$ tarafından Sınıf 3 kapanış bozukluğuna sahip 30 cerrahi hastasında maksiller ilerletme ve mandibular geri alma cerrahi- sinin stabilitesini karşılaştırmak amacıyla yapılan çalışmada, maksiller cerrahide relaps oranı \%21, mandibular cerrahide \%27 bulunmuştur. Çalışmada yapılması mümkünse maksiller cerrahi yapıldığında sonuçların daha stabil olduğu sonucuna varılmıştır.

\section{Maksiller sarkıtma:}

Quejada ve ark. ${ }^{39}$ maksiller sarkıtma hareketinin stabil bir durum olmadığını, tel fiksasyon uyguladıkları hastalarında intermaksiller fiksasyon sırasında \%50 oranında relaps görüldüğünü, kalan relapsın ise cerrahiden sonraki ilk 6 ay içinde gerçekleştiğini bildirmişlerdir.

\section{Maksiller geri alma:}

Chouet-Girard ve Mercier ${ }^{40}$, maksiller geri alma cerrahisi uyguladıkları 11 hasta üzerinde diagnostik ve teknik zorluklara rağmen stabil ve başarılı sonuçlar elde ettiklerini rapor etmişlerdir. Han ve Hwang $^{41}$, maksiller geri alma cerrahisinden sonra pterygomaksiller bölgedeki iyileşmeyi ve stabiliteyi değerlendirmek amacıyla yaptıkları çalışmada, maksiller aşırılığa sahip 27 hastanın üç boyutlu radyografik görüntülerini değerlendirmişlerdir. Sonuc olarak cerrahiden 6 ay sonra horizontal ve vertikal düzlemde anlamlı relaps bulamamışlardır. Ayn zamanda yazarlar geri alma miktarındaki artışın relapsı artırmadığını da rapor etmişlerdir.

\section{Mandibular ilerletme:}

Epker ve ark. ${ }^{13}$ mandibular ilerletme cerrahisinin horizontal büyüme yönü olan vakalarda daha başarılı ve stabil olduğunu rapor etmişlerdir.

Rao ve diğerleri ${ }^{42}, 10$ hasta üzerinde yaptıkları bir çalışmada mandibular ilerletme cerrahisinden sonra relapsın 3. ayda meydana geldiğini rapor etmişlerdir.

Mandibular ilerletme cerrahilerinde genellikle rijit fiksasyon tercih edilmektedir. Bunun sebebi intermaksiller fiksasyona gerek kalmadan kemik iyileşmesinin hızlandırılması ve erken dönemde relaps miktarının azaltılarak mandibula fonksiyonlarına mümkün olduğunca erken dönemde başlanmasıdır. ${ }^{43}$

\section{Mandibular Geri Alma:}

Rao ve ark. ${ }^{42}$, 10 hasta üzerinde yaptıkları bir çalışmada mandibular geri alma cerrahisinden sonra relapsın 6. ayda meydana geldiği rapor etmişlerdir.

Han ve ark. ${ }^{44}$ tarafından mandibular geri alma cerrahisinde relapsın geri alma miktarından mı yoksa proksimal segmentlerin rotasyon miktarından mı kaynaklandığını tespit etmek için yapılan çalışmada, 36 iskeletsel Sınıf 3 hasta cerrahiden sonra 6 ay süreyle takip edilmiş ve sonuç olarak relapsın hareket miktarından çok rotasyondan kaynaklandığı belirtilmiştir. Eğer cerrahi işlem sırasında rotasyonel kontrol sağlanırsa stabilitenin daha iyi olacağı vurgulanmıştır.

\section{Asimetri düzeltimi:}

Hagensli ve ark.larının ${ }^{45}$ mandibular aşırılık ve $4 \mathrm{~mm}$ 'den fazla asimetriye sahip bilateral sagital split osteotomisi yapılan 38 hastada uzun dönem stabilite, relaps zamanı, miktarı, duyusal bozukluklar ve hasta memnuniyetini değerlendirmek için yaptıkları retrospektif çalışmada cerrahiden hemen sonra, 6 ay sonra ve 3 yıl sonra sefalometrik filmler ve anketler değerlendirilmiş sonuç olarak asimetri düzeltiminin stabil olduğu bildirilmiştir. En fazla relaps olasılığı 6 ay

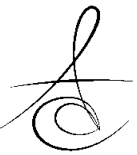


içinde olurken, 3 yıl sonra hastaların \%58'inde $3 \mathrm{~mm}$ asimetri bulunduğu rapor edilmiştir. Aynı çalışmada 2'si hariç tüm hastalar 3 yıl sonra bile durumlarından memnun olduklarını belirtmişlerdir.

Yoo ve ark. $^{46}$ tarafindan asimetrisi olan ve olmayan Sinf 3 vakalarda mandibular geriletme sonrası proksimal segmentlerin transvers stabilitesini karşılaştırmak amacıyla en az 2 aylık takiple yapılan çalışmada gruplar arasında anlamlı farklılık bulunmamıştır.

16) Malokluzyon türü:

- İskeletsel Sınıf 2 ve Sınıf 3 hastalarda stabilite:

Bailey ve $\operatorname{ark}^{47}$ tarafından yapılan bir çalışmada ortognatik cerrahi uygulanan Sınıf 2 vertikal yön büyümesine sahip hastalar ilk 1 yılda sınıf 3 hastalardan daha stabil bulunurken, 1-5 yll arası dönemde Sınıf 3 hastalar daha stabil bulunmuştur.

İskeletsel Sınıf 2 ve Sınıf 3 hastalarda uzun dönem stabiliteyi karşılaşıımak için yapılan çalışmada hastalar 4 gruba ayrımışır. İskeletsel Sınıf 2 hastalardan oluşan 1. gruba mandibular ilerletme, 2. gruba maksiller gömme ve mandibular ilerletme yapılmıştır. İskeletsel Sınıf 3 hastalardan oluşan 3. gruba maksiller ilerletme, 4. gruba maksiller ilerletme ve mandibular geriletme yapılmış ve hastaların tümü en az 3 yıl süreyle takip edilmiştir. Sonuç olarak 1 . ve 2 . grupta yani Sınıf 2 hastalarda relaps miktarı mandibular düzlem açısında artış nedeniyle Sınıf 3 hastalardan daha fazla bulunmuştur. ${ }^{48}$

Vertikal yön büyümesi olan Sınıf 3 yapıya sahip 19 hastada maksiller ilerletme, mandibular geriletme ve mandibular rotasyon yapılmış ve hastaların en az 6 yıllık takibi sonucunda ramus açısı, gonial açı ve mandibular düzlem açısında anlamlı relaps miktarları görülmüştür. Sonuç olarak horizontal yön büyümesine sahip olan vakaların daha stabil olduğu vurgulanmıştır. ${ }^{11}$

\section{- Açık kapanış hastalarında stabilite:}

Açık kapanışa sahip hastalarda standart cerrahi işlem maksiller gömme ile birlikte çift çene cerrahi yapılmasıdır. Ancak günümüzde bazı durumlarda rijit internal fiksasyonla tek çene mandibular cerrahi de uygulanmaya başlanmıştır. Bu yöntemin stabilitesini araştırmak amacıyla Fontes ve ark. ${ }^{49}$ tarafindan yapılan çalışmada 31 hastaya ortalama 3,7 derece mandibular rotasyon yaptııımış, cerrahiden 4,5 yıl sonra sadece 3 hastada overbite olmadığı görülmüş- tür. Cerrahi ile elde edilen rotasyon miktarının \%60'ının kaybına rağmen pozitif overbite varlığı nedeniyle bu yöntem çift çene cerrahiye alternatif stabil bir yöntem olarak tanıtılmıştır.

Silva ve ark.larııı ${ }^{50}$ çalışmasında rijit fiksasyon kullanılarak maksillada açık kapanı̧̧ cerrahisi yapılan 33 hasta cerrahiden sonra 6. , 12. , 18. ve 30. aylarda stabilite açısından değerlendirilmiş ve sonuç olarak oluşan relapsın cerrahiden sonra 1 . ayda vertikal yönde olduğu belirtilmiştir. Mandibulanın sagittal pozisyonunda bir değişiklik saptanmamıştır.

Açık kapanı̧̧ düzeltimi için cerrahi uygulanan hastalar üzerinde yapılan bir çalışmada vertikal yöndeki relapsın daha çok uzun dönemde meydana geldiği rapor edilmiştir. ${ }^{51}$

Maia ve ark..$^{52}$ tarafından yapılan çalışmada ise, iskeletsel Sınıf 1 , Sınıf 2 ve Sınıf 3 açık kapanış hastalarından oluşan tek ya da çift çene cerrahi yapılan 39 hasta, cerrahi sonrası ortalama 8 yllık takipte istatistiksel olarak anlamlı relaps göstermişlerdir. Relaps oranları iskeletsel Sınıf 1 , Sınıf 2 ve Sinif 3 hastalarda sirasiyla $\% 64, \% 47$ ve $\% 87$ 'dir. 14 hasta ise negatif overbite durumuna geçmiştir.

\section{-Damak dudak yarıklı hastalarda stabilite:}

Damak dudak yarığı hastalarında normal orofonksiyonel etkiler elde edebilmek için stabilite şarttır. Maksillanın üç boyutlu yetersizliğinin düzeltiminde daha önceki çalışmalarda ortognatik cerrahi işlemler denense de, günümüzde aşırı skar dokusu nedeniyle distraksiyon osteogenezisi önerilmektedir. ${ }^{53,54}$

Chua ve diğerlerinin ${ }^{55}$ distraksiyon osteogenezisi ve ortognatik cerrahi uygulanan damak dudak yarıklı hastaları 5 yıl sonra stabilite açısından değerlendirdikleri çalışmada, maksilla konvansiyonel cerrahi sonucunda yukariya ve geriye relaps yaparken distraksiyonla aşağı öne relapsa uğramış, böylece maksillanın pozisyonunun distraksiyon sonucunda daha stabil olduğu bulunmuştur.

Aksu ve ark. ${ }^{56}$ yetişkin 7 damak dudak yarıklı hastada maksiller distraksiyon sonrası dental ve iskeletsel stabiliteyi değerlendirmek amacıyla yaptıkları çalışmada, distraksiyon sonrasında maksillanın saat yönünün tersine rotasyon yaptığını, maksiller keserlerin labiyale eğimlendiğini ve maksiller molarların meziyal angulasyona uğradığını tespit etmişlerdir. 
Distraksiyondan 3 yıl sonra takip değerlendirmesinde ise, maksillada \%22 oranında relapsla birlikte maksillanın saat yönünün tersine rotasyonunun önceki durumuna geri döndüğünü rapor etmişlerdir.

Saltaji ve ark.larının ${ }^{57}$ yaptıkları çalışmada, dudak damak yarığına sahip hastalarda konvansiyonel cerrahi ile maksiller ilerletme sonucunda horizontal düzlemdeki relaps miktarı orta derecede iken vertikal düzlemdeki relaps miktarı yüksek bulunmuştur.

Kumari ve ark. ${ }^{58}$ maksiller ilerletme cerra- hisi uygulanan 9 damak dudak yarıklı hastanın cerrahi sonrası 15. gün ve 12 . ayda relaps miktarlarını değerlendirmek amacıyla bir çalışma yapmışlardır. Çalışmada yazarlar horizontal relaps miktarını \%21, vertikal relaps miktarını ise \%41 bulmuşlar, rijit fiksasyonla relaps oranının azaltılabildiğini, ancak yine de distraksiyon kadar stabilite sağlanamadığını bildirmişlerdir.

\section{Sonuç olarak;}

Ortognatik cerrahi tedavinin stabilitesi yukarıda anlatıldığı gibi birçok faktörle ilişkili olabilir. Yeterli stabilite elde edilebilmesi için hem ortodontist hem de cerrah üzerine düşen görevleri dikkatle yerine getirmelidir.

\section{KAYNAKLAR}

1. Graber T, Vanarsdall R, Vig K. Orthodontics: Current Principles and Techniques. Fifth Edition. Mosby 2012: p.944-51.

2. Proffit WR, White RP. Treatment of severe malocclusions by correlated orthodontic-surgical procedures. Angle Orthod 1970; 40: 1-10.

3. Giray B, Aktaş A, Öktemer K, Taner T, Akcan C, Meral G, Ökten S. Yetişkin Hastada Kondiler Hiperplazi: Vaka Raporu. Hacettepe Diş Hekimliği Fakültesi Dergisi 2008; 32: 45-50.

4. Bellucci CC, Kapp-Simon KA. Psychological considerations in orthognathic surgery. Clin Plast Surg 2007; 34: 11-6.

5. Snow MD, Turvey TA, Walker D, Proffit WR. Surgical mandibular advancement in adolescents: postsurgical growth related to stability. Int J Adult Orthodon Orthognath Surg 1991; 6: 143-51.

6. Kersey ML, Nebbe B, Major PW. Temporomandibular joint morphology changes with mandibular advancement surgery and rigid internal fixation: a systematic literature review. Angle Orthod 2003; 73: 79-85.
7. Gunson MJ, Arnett GW, Formby B, Falzone C, Mathur R, Alexander $\mathrm{C}$. Oral contraceptive pill use and abnormal menstrual cycles in women with severe condylar resorption: a case for low serum 17beta-estradiol as a major factor in progressive condylar resorption. Am J Orthod Dentofacial Orthop 2009; 136: 772-9.

8. Moore $\mathrm{KE}$, Gooris $\mathrm{PJ}$, Stoelinga PJ. The contributing role of condylar resorption to skeletal relapse following mandibular advancement surgery: report of five cases. J Oral Maxillofac Surg 1991; 49: 448-60.

9. Kim YJ, Lee $Y$, Chun YS, Kang N, Kim SJ, Kim M. Condylar positional changes up to 12 months after bimaxillary surgery for skeletal class III malocclusions. J Oral Maxillofac Surg 2014; 72: 145-56.

10. Acun Kaya F, Darı O, Özbaş Y, Darı O. Lokalize Agresif Periodontitiste Kombine Ortodontik Periodontal Tedavi: Olgu Sunumu. Atatürk Üniversitesi Diş Hekimliği Fakültesi Dergisi. 2005; 15: 98-102.

11. Gallego-Romero D, Llamas-Carrera JM, TorresLagares D, Paredes V, Espinar E, Guevara E, Gutierrez-Perez JL. Long-term stability of surgicalorthodontic correction of class III malocclusions with long-face syndrome. Med Oral Patol Oral Cir Bucal 2012; 17: 435-41.

12. Vanarsdall RL. Transverse dimension and longterm stability. Semin Orthod 1999; 5: 171-80.

13. Epker BN, Wolford LM, Fish LC. Mandibular deficiency syndrome. II. Surgical considerations for mandibular advancement. Oral Surg Oral Med Oral Pathol 1978; 45: 349-63.

14. Wickwire NA, White RP, Jr., Proffit WR. The effect of mandibular osteotomy on tongue position. J Oral Surg 1972; 30: 184-90.

15. Poulton DR, Ware WH. Surgical-orthodontic treatment of severe mandibular retrusion. Am J Orthod 1971; 59: 244-65.

16. McNeill RW, Hooley JR, Sundberg RJ. Skeletal relapse during intermaxillary fixation. J Oral Surg 1973; 31: 212-27.

17. Steinhauser EW. Advancement of the mandible by sagittal ramus split and suprahyoid myotomy. ] Oral Surg 1973; 31: 516-21. 
18. Guernsey LH. Stability of treatment results in class II malocclusion corrected by full mandibular advancement surgery. Oral Surg Oral Med Oral Pathol 1974; 37: 668-87.

19. Bailey L, Cevidanes LH, Proffit WR. Stability and predictability of orthognathic surgery. Am J Orthod Dentofacial Orthop 2004; 126: 273-7.

20. Kim CS, Lee SC, Kyung HM, Park HS, Kwon TG. Stability of mandibular setback surgery with and without presurgical orthodontics. J Oral Maxillofac Surg 2014; 72: 779-87.

21. Ko EW, Hsu SS, Hsieh HY, Wang YC, Huang CS, Chen YR. Comparison of progressive cephalometric changes and postsurgical stability of skeletal Class III correction with and without presurgical orthodontic treatment. J Oral Maxillofac Surg 2011; 69: 1469-77.

22. Hartlev J, Godtfredsen E, Andersen NT, Jensen T. Comparative Study of Skeletal Stability between Postoperative Skeletal Intermaxillary Fixation and No Skeletal Fixation after Bilateral Sagittal Split Ramus Osteotomy: an 18 Months Retrospective Study. J Oral Maxillofac Res 2014; 5: e2.

23. Krekmanov L, Lilja J. Orthognathic surgery with no postoperative intermaxillary fixation. Scand J Plast Reconstr Surg Hand Surg 1987; 21: 189-97.

24. Krekmanov L. Orthognathic surgery without the use of postoperative intermaxillary fixation. A clinical and cephalometric evaluation of surgical correction of mandibular and maxillary deformities. Swed Dent J Suppl 1989; 61: 8-62.

25. Proffit WR, Phillips C, Turvey TA. Stability after mandibular setback: mandible-only versus 2-jaw surgery. J Oral Maxillofac Surg 2012; 70: 408-14.

26. Al-Delayme R, Al-Khen M, Hamdoon Z, Jerjes W. Skeletal and dental relapses after skeletal class III deformity correction surgery: single-jaw versus double-jaw procedures. Oral Surg Oral Med Oral Pathol Oral Radiol 2013; 115: 466-72.

27. Van Sickels JE, Richardson DA. Stability of orthognathic surgery: a review of rigid fixation. $\mathrm{Br}$ J Oral Maxillofac Surg 1996; 34: 279-85.

28. Arnett GW, Milam SB, Gottesman L. Progressive mandibular retrusion--idiopathic condylar resorption. Part I. Am J Orthod Dentofacial Orthop 1996; 110: 8-15.

29. Merkx MA, Van Damme PA. Condylar resorption after orthognathic surgery. Evaluation of treatment in 8 patients. J Craniomaxillofac Surg 1994; 22: 53-8.

30. Mavili ME, Canter HI, Saglam-Aydinatay B. Semirigid fixation of mandible and maxilla in orthognathic surgery: stability and advantages. Ann Plast Surg 2009; 63: 396-403.

31. Blomqvist JE, Isaksson S. Skeletal stability after mandibular advancement: a comparison of two rigid internal fixation techniques. J Oral Maxillofac Surg 1994; 52: 1133-7.

32. Ellis E, 3rd, Carlson DS, Frydenlund S. Stability of midface augmentation: an experimental study of musculoskeletal interaction and fixation methods. J Oral Maxillofac Surg 1989; 47: 1062-8; discussion 8-9.

33. Proffit WR, Turvey TA, Phillips C. Orthognathic surgery: a hierarchy of stability. Int J Adult Orthodon Orthognath Surg 1996; 11: 191-204.

34. Proffit WR, Phillips C, Turvey TA. Stability following superior repositioning of the maxilla by LeFort I osteotomy. Am J Orthod Dentofacial Orthop 1987; 92: 151-61.

35. Bailey LJ, Phillips C, Proffit WR, Turvey TA. Stability following superior repositioning of the maxilla by Le Fort I osteotomy: five-year followup. Int J Adult Orthodon Orthognath Surg 1994; 9: 163-73.

36. Luyk NH, Ward-Booth RP. The stability of Le Fort I advancement osteotomies using bone plates without bone grafts. J Maxillofac Surg 1985; 13: 250-3.

37. Louis PJ, Waite PD, Austin RB. Long-term skeletal stability after rigid fixation of Le Fort I osteotomies with advancements. Int J Oral Maxillofac Surg 1993; 22: 82-6.

38. de Haan IF, Ciesielski R, Nitsche T, Koos B. Evaluation of relapse after orthodontic therapy combined with orthognathic surgery in the treatment of skeletal class III. J Orofac Orthop 2013; 74: 362-9.

39. Quejada JG, Bell WH, Kawamura H, Zhang X. Skeletal stability after inferior maxillary repositioning. Int J Adult Orthodon Orthognath Surg 1987; 2: 67-74.

40. Chouet-Girard F, Mercier J. [Total osteotomy for maxillary setback. Indications, technique, results]. Rev Stomatol Chir Maxillofac 2003; 104: 317-25. 
41. Han JJ, Hwang SJ. Evaluation of early postoperative healing of pterygomaxillary region after LeFort I osteotomy with total maxillary setback movement. Oral Surg Oral Med Oral Pathol Oral Radiol 2014; 118: 647-54.

42. Rao SH, Selvaraj L, Lankupalli AS. Skeletal stability after bilateral sagittal split advancement and setback osteotomy of the mandible with miniplate fixation. Craniomaxillofac Trauma Reconstr 2014; 7: 9-16.

43. Tharanon W. Comparison between the rigidity of bicortical screws and a miniplate for fixation of a mandibular setback after a simulated bilateral sagittal split osteotomy. J Oral Maxillofac Surg 1998; 56: 1055-8.

44. Han JJ, Yang HJ, Lee SJ, Hwang SJ. Relapse after SSRO for mandibular setback movement in relation to the amount of mandibular setback and intraoperative clockwise rotation of the proximal segment. J Craniomaxillofac Surg 2014; 42: 8115.

45. Hagensli N, Stenvik A, Espeland L. Asymmetric mandibular prognathism: Outcome, stability and patient satisfaction after BSSO surgery. A retrospective study. J Craniomaxillofac Surg 2014; 42: 1735-41.

46. Yoo JY, Kwon YD, Suh JH, Ko SJ, Lee B, Lee JW, Kim EC, Girod S. Transverse stability of the proximal segment after bilateral sagittal split ramus osteotomy for mandibular setback surgery. Int J Oral Maxillofac Surg 2013; 42: 994-1000.

47. Bailey L, Duong HL, Proffit WR. Surgical Class III treatment: long-term stability and patient perceptions of treatment outcome. Int J Adult Orthodon Orthognath Surg 1998; 13: 35-44.

48. de Lir Ade L, de Moura WL, Oliveira Ruellas AC, Gomes Souza MM, Nojima LI. Long-term skeletal and profile stability after surgical-orthodontic treatment of Class II and Class III malocclusion. ] Craniomaxillofac Surg 2013; 41: 296-302.

49. Fontes AM, Joondeph DR, Bloomquist DS, Greenlee GM, Wallen TR, Huang GJ. Long-term stability of anterior open-bite closure with bilateral sagittal split osteotomy. Am J Orthod Dentofacial Orthop 2012; 142: 792-800.

50. Silva I, Suska F, Cardemil C, Rasmusson L. Stability after maxillary segmentation for correction of anterior open bite: a cohort study of
33 cases. J Craniomaxillofac Surg 2013; 41: 1548.

51. Solano-Hernandez B, Antonarakis GS, Scolozzi P, Kiliaridis $S$. Combined orthodontic and orthognathic surgical treatment for the correction of skeletal anterior open-bite malocclusion: a systematic review on vertical stability. J Oral Maxillofac Surg 2013; 71: 98-109.

52. Maia FA, Janson G, Barros SE, Maia NG, Chiqueto K, Nakamura AY. Long-term stability of surgicalorthodontic open-bite correction. Am J Orthod Dentofacial Orthop 2010; 138: 254 e1- e10; discussion -6.

53. Yavuz A, Aksu M. Long term stability of maxillary retrusion treatment with external distraction. Turkish Plast Surg 2013; 21: 8-13.

54. Paulus C. Orthognathic surgery for patients with cleft lip and palate. Rev Stomatol Chir Maxillofac Chir Orale 2014; 115: 239-44.

55. Chua HD, Hagg MB, Cheung LK. Cleft maxillary distraction versus orthognathic surgery--which one is more stable in 5 years? Oral Surg Oral Med Oral Pathol Oral Radiol Endod 2010; 109: 803-14.

56. Aksu M, Saglam-Aydinatay B, Akcan CA, El H, Taner T, Kocadereli I, Tuncbilek G, Mavili ME. Skeletal and dental stability after maxillary distraction with a rigid external device in adult cleft lip and palate patients. J Oral Maxillofac Surg 2010; 68: 254-9.

57. Saltaji H, Major MP, Alfakir H, Al-Saleh MA, FloresMir C. Maxillary advancement with conventional orthognathic surgery in patients with cleft lip and palate: is it a stable technique? J Oral Maxillofac Surg 2012; 70: 2859-66.

58. Kumari P, Roy SK, Roy ID, Kumar P, Datana S, Rahman S. Stability of Cleft maxilla in Le Fort I Maxillary advancement. Ann Maxillofac Surg 2013; 3: $139-43$.

\section{Yazışma Adresi}

Dt. Emel YEŞİL ŞAHİN

Hacettepe Üniversitesi

Diş Hekimliği Fakültesi

Ortodonti Anabilim Dalı

7.Kat -ANKARA

TIf: 03123052290

e-mail: emelyesil87@gmail.com 